\title{
Country, Sex, and Parent Occupational Status: Moderators of the Continuity of Aggression from Childhood to Adulthood
}

\author{
Katja Kokko $^{1 *}$, Sharon Simonton ${ }^{2}$, Eric Dubow ${ }^{2,3}$, Jennifer E. Lansford ${ }^{4}$, Sheryl L. Olson ${ }^{2}$, \\ L. Rowell Huesmann ${ }^{2}$, Paul Boxer ${ }^{5}$, Lea Pulkkinen ${ }^{1}$, John E. Bates ${ }^{6}$, Kenneth A. Dodge ${ }^{4}$, \\ and Gregory S. Pettit ${ }^{7}$
}

${ }^{1}$ University of Jyvaskyla, Jyvaskyla, Finland

${ }^{2}$ University of Michigan, Ann Arbor, Michigan

${ }^{3}$ Bowling Green State University, Bowling Green, Ohio

${ }^{4}$ Duke University, Durham, North Carolina

${ }^{5}$ Rutgers University, Newark, New Jersey

${ }^{6}$ Indiana University, Bloomington, Indiana

${ }^{7}$ Auburn University, Auburn, Alabama

: : : : : : : : : : : : : : : : : : : : : : : : : : : : : : : : : : : : :

Using data from two American and one Finnish long-term longitudinal studies, we examined continuity of general aggression from age 8 to physical aggression in early adulthood (age 21-30) and whether continuity of aggression differed by country, sex, and parent occupational status. In all samples, childhood aggression was assessed via peer nominations and early adulthood aggression via self-reports. Multi-group structural equation models revealed significant continuity in aggression in the American samples but not in the Finnish sample. These relations did not differ by sex but did differ by parent occupational status: whereas there was no significant continuity among American children from professional family-of-origin backgrounds, there was significant continuity among American children from non-professional backgrounds. Aggr. Behav. 40:552-567, 2014. (c) 2014 Wiley Periodicals, Inc.

: : : : : : : : : : : : : : : : : : : : : : : : : : : : : : : :

Keywords: aggression; continuity; cross-national; longitudinal study; occupational status; structural equation model

\section{INTRODUCTION}

The long-term continuity of aggressive behavior has been likened to that of general intelligence (Olweus, 1979). Individual differences in aggressive behavior have been found to be fairly stable across large spans of development spanning middle childhood through adulthood (e.g., Farrington \& West, 1990; Huesmann, Dubow, \& Boxer, 2009; Huesmann, Eron, \& Dubow, 2002; Huesmann, Eron, Lefkowitz, \& Walder, 1984; Kokko \& Pulkkinen, 2005; Magnusson, 1988; Pulkkinen \& Pitkänen, 1993). Recent longitudinal findings have suggested that the long-term continuity of children's aggressive behavior differs according to the type of aggressive behavior (e.g., direct physical vs. other forms) and measures of aggression, the sex of the child, and the child's cultural background (Kokko, Pulkkinen, Huesmann, Dubow, \& Boxer, 2009). Importantly, differences in the item content of measures have
Contract grant sponsor: USA National Science Foundation (NSF); contract grant number: 0818478; contract grant sponsor: Academy of Finland; contract grant numbers: 118316, 135347, 127125; contract grant sponsor: Columbia County (NY) Tuberculosis and Health Association and the Hudson (NY) Lions Club; contract grant sponsor: USA National Institute of Mental Health; contract grant sponsor: National Institute of Child Health and Human Development; contract grant sponsor: USA National Institute of Mental Health; contract grant numbers: MH42498, MH56961, MH57024, MH57095; contract grant sponsor: Eunice Kennedy Shriver National Institute of Child Health and Human Development; contract grant number: HD30572; contract grant sponsor: National Institute on Drug Abuse; contract grant number: DA016903. Conflicts of interest: None.

${ }^{*}$ Correspondence to: Katja Kokko, Gerontology Research Center, Department of Health Sciences, P.O. Box 35, 40014 University of Jyvaskyla, Finland. E-mail: katja.r.kokko@jyu.fi

Received 28 August 2013; Accepted 7 May 2014

DOI: $10.1002 / \mathrm{ab} .21546$

Published online 2 July 2014 in Wiley Online Library

(wileyonlinelibrary.com). 
prevented direct comparisons across longitudinal studies conducted in different countries.

Kokko et al. (2009) compared, using similar items to assess aggression, the long-term continuity of different forms of aggression in males and females in the USA and Finland. These countries provided an advantageous comparison because Finland and the United States have different levels of violence. For example, homicide rates in the USA are more than twice as high as those in Finland (United Nations Office on Drugs and Crime, 2013). The Finnish sample was drawn from the Jyväskylä Longitudinal Study of Personality and Social Development (JYLS) in which 369 individuals were by then assessed at ages $8,14,27,36$, and 42 . When children were 8 years old, aggressive behavior was defined based on an average of 10 peer nominated items. The peer nomination measure included a mixture of different types of aggressive behavior: proactive, reactive, direct, and indirect aggressive behavior displayed physically, verbally, and facially. For clarification, it should be noted that indirect aggression is often used interchangeably to describe social and relational manipulative aggression (see, e.g., Archer \& Coyne, 2005). However, we use the direct versus indirect distinction also to indicate the direction of an aggressive act, whether it is intended directly at a target (e.g., another child) or indirectly at a target (e.g., through kicking objects when angry; Pitkänen, 1969). Furthermore, by physical aggression we refer to a physical mode of aggression, targeted at either other people or objects. Age-adjusted peer nominations of aggressive behavior also were obtained when children were 14 years of age (Kokko et al., 2009). At ages 36 and 42, individuals in the JYLS rated seven items indicating their propensity to hit when angry, and tendency to verbally lash out and poor temper control.

Comparable data from the USA were drawn from the Columbia County Longitudinal Study (CCLS; Eron, Walder, \& Lefkowitz, 1971; Huesmann et al., 1984; Huesmann, Dubow, Eron, \& Boxer, 2006). In this study, 856 children were assessed at ages $8,19,30$, and 48 . As with the JYLS, child and adolescent measures of aggressive behavior in the CCLS were based on 10 peer nominations of physical and verbal aggression. At ages 30 and 48, CCLS participants provided self-ratings on four items reflecting severe physical aggression (choked, punched, hit, threatened with weapon), and four items reflecting milder physical aggression (e.g., starts a fight over nothing), as well as four items reflecting verbal aggression (e.g., feel like screaming, fighting, arguing).

In both samples, there was substantial continuity from aggression at age 8 to aggression at ages 14-19 to physical aggression by age 42-48, but continuity coefficients from adolescence to adulthood were higher among the American than Finnish participants, and within the USA, higher among male than female participants (Kokko et al., 2009). Conversely, there was no significant continuity in either country from childhood aggression to adult verbal aggression. The authors argued that there is probably a stronger biological basis for physical than for verbal aggression, which could account for the greater stability over time of physical aggression; verbal aggression may be more influenced by situational factors. Genetically informed studies provide indirect support for this notion (e.g., Brendgen et al., 2005; Eley, Lichtenstein, \& Moffitt, 2003). In terms of the country differences, Kokko et al. (2009) noted a number of methodological differences in the measures used in the two countries. The items at age 8 were very similar in the CCLS and JYLS, but the physical aggression items in adulthood were more severe in nature in the USA study, which might account for the higher levels of continuity in physical aggression in the CCLS sample.

In the present study, we sought to extend the findings of Kokko et al. (2009) based on the JYLS and CCLS to include another sample from the USA, the Child Development Project (CDP) (Dodge, Bates, \& Pettit, 1990), that represents a different historical cohort of children born in the 1980s. By comparing results from the two American samples, we could assess whether cohort differences affect the magnitude of continuity. In all three samples, we restricted the analyses to items that are highly comparable across data sets (general aggression in middle childhood assessed at age 8 through peer nominations; physical aggression in early adulthood, ages $21-30$, assessed through self-reports) and use early adulthood as an endpoint in all three studies. We focus on the prediction of physical aggression in early adulthood even though Tremblay (2010) has found that physical aggression peaks around ages 2-4 years. Within adulthood most criminal acts are conducted in young adulthood (Tremblay, 2012), particularly violent crimes (Sampson \& Laub, 2003) and Archer (2004) has shown that sex differences in the amount of physical aggression are at the highest level in early adulthood (at age 21-30); men use more physical aggression than women. Thus, the present study design allowed us to examine differences in continuity across countries and sex using comparable measures of aggression at similar ages. We also examined whether the Kokko et al. finding of a lower magnitude of continuity of aggression in Finland than the USA is related to differences in the role of childhood parent occupational status and its relations with childhood aggression in the two countries.

\section{Sex Differences in Continuity of Aggression}

By "continuity" in aggression over time, we mean the degree to which individuals retain their relative positions 
on aggression within the population across time points. It is important to realize that high continuity of aggression means both that highly aggressive individuals are tending to stay high in aggression over time but also that less aggressive individuals are tending to stay low in aggression over time (Huesmann et al., 2009). The longterm continuity of children's aggressive behavior has been documented in many prior longitudinal studies (Olweus, 1979). Across childhood and early adolescence, the continuity of aggressive behavior was found to be similar among girls and boys in the study by Cairns, Cairns, Neckerman, Ferguson, and Gariépy (1989). Those authors reported continuities in teacher-rated aggression from age 9 to 13 to be .51 for USA girls and .49 for boys. In the Finnish JYLS study, continuity was equal among boys and girls from age 8 to 14 when aggression was measured by peer nomination $(r=.37$ for both sexes, $P<.001)$, but there was a statistically significant sex difference in the continuity of aggression when teacher ratings were employed $(r=.37$ for boys, $P<.001,0.13$ for girls, n.s.; Pitkänen-Pulkkinen, 1981). A higher continuity in teacher-rated aggression among boys than among girls from age 12 to 14 was also found in a large Finnish twin-sample $(r \sim .30$ for boys and 0.20 for girls; Vierikko, Pulkkinen, Kaprio, \& Rose, 2006). When composite scores of peer nominations and teacher ratings were used in the JYLS, the correlations between aggression scores at ages 8 and 14 did not differ significantly between the sexes (.33 for girls and .38 for boys; Kokko \& Pulkkinen, 2005). Likewise, Huesmann (2001), using data from a study conducted in the USA in Illinois, reported non-significant differences in continuities of aggression from age 6 through 11 ( $r=.47$ for boys and 0.50 for girls), when a composite score of peer nominations and teacher reports was used.

From middle to later adolescence, similar continuities were reported for both sexes by Huesmann et al. (1984) who found in the USA CCLS a correlation 0.44 for boys and 0.36 for girls in peer-nominated aggression from age 8 to age 19. Nevertheless, Pulkkinen and Pitkänen (1993), in the Finnish JYLS, did not find significant continuity from age 8 peer nominated- and teacher-rated aggression to self-reported aggression at age 27 (correlations were, respectively, 0.13 and 0.14 for males, and 0.13 and 0.08 for females).

\section{Country Differences in Continuity of Aggression}

Differences in the continuity of aggression have been reported across samples from different countries. Huesmann and colleagues (Huesmann \& Eron, 1986; Huesmann \& Moise, 1998; The Cross-National Television Study) reported on the continuity of aggression in four countries (United States, Finland, Poland, and Israel) between ages 6-10 and 21-25. In childhood, aggression was assessed through peer nominations; in early adulthood, aggression was defined as a composite index of physical, verbal, and indirect aggression reported by oneself and others. In all four countries there was high continuity of aggression in boys and girls over the 3 years of assessments during the $6-10$ age period (.57-.82). For the follow-up data acquired 15 years later, there was moderate continuity in aggressive behavior for males and females in the USA and Finland. In Poland, only males showed significant continuity of aggressive behavior. Finally, in Israel, there was only weak evidence for continuity of aggression for males and no evidence of continuity for females (Huesmann \& Moise, 1998).

\section{Predicted Socioeconomic Differences in the Continuity of Aggression Between Finland and the USA}

Finland is a country characterized by high social equality. Compared to the USA, there are fewer cultural differences between children from differing socioeconomic status (SES) backgrounds. In countries characterized by social equality (e.g., Finland), there are fewer differences among children in, for example, their school achievement, school dropout rate, health and social problems, and trust in people, than in children from countries with less social equality (e.g., USA; Wilkinson \& Pickett, 2010). In Finland, social justice is highly valued in the school system and dropout is rare (Sahlberg, 2011). Residential area is the major factor determining the child's school and residential areas are more socioeconomically mixed than in the USA, meaning that children from various SES backgrounds attend the same schools in Finland (Sahlberg, 2011). According to the Organisation for Economic Co-operation and Development (OECD, 2011), upper secondary education graduation rates (which include vocational schooling) were $95 \%$ in Finland, compared to $76 \%$ in the USA in 2009. In the OECD (2011) comparison, upper secondary education refers to education that prepares students for further, mainly theory-based, studies. The ages of graduates were on average 17-20 years (in Finland, 10\% of the first-time graduates were 25 years). Further, the Programme for International Student Assessment (PISA) comparisons show that Finnish students do academically well in achievement tests (science, reading, math), and that test score differences between schools in the PISA results are exceptionally small (Sahlberg, 2011). According to Sahlberg (2011), one reason for the high academic skills of the Finnish students may be the fact that all Finnish teachers have to hold a master's degree from the university, whereas in the USA this kind of qualification is not required. Also, upward social mobility is quite common in Finland (e.g., Lynch, Kaplan, \& Salonen, 1997; Wilkinson 
\& Pickett, 2010). Social mobility is enhanced by the fact that higher education is free and state-supported in Finland. Thus, we predicted that aggressive children from low SES families (operationalized by low parent occupational status) in Finland may have more resources than the American children and that these resources might serve as a protective factor that would decrease the likelihood of aggressive Finnish children remaining aggressive by young adulthood.

\section{The Present Study}

Combined with the cross-cultural aggression continuity findings of Huesmann and Moise (1998), the findings of Kokko et al. (2009) suggest that the continuity aggressive behavior between childhood and adulthood is moderated by sex and cultural context. These intriguing findings have raised important interpretive questions, such as, are these "real" cultural differences or do the findings reflect differences across studies in measures of aggression and historical cohorts? Thus, we sought to extend the findings of Kokko et al. in several ways. First, we chose both childhood and adult aggression items that were nearly identical for all participants across the two countries. Second, we included a second USA sample born in the 1980s (the Child Development Project; Dodge et al., 1990) to compare continuities in this sample with those obtained in the CCLS and JYLS with participants born in the 1950s. We expected that continuities in aggression would be similar for the two USA cohorts. Third, we examined continuities from general aggression in childhood to physical aggression in adulthood, but we used the early adulthood period that corresponded well to assessment points in all three studies. We expected to find significant continuity of aggression across samples. In particular, in both countries, we expected that children high in aggression would remain high in early adulthood but that continuity of aggression would be stronger in the American samples than in the Finnish sample. Fourth, we examined whether sex moderated the continuity of aggression from childhood to early adulthood. We expected that there would be stronger continuity of aggression among males than females across the samples. Finally, we examined whether continuity in aggression might be moderated by parent occupational status. We expected to find more stability in aggression among the American children from lower parent occupational status backgrounds than for Finnish participants from comparable backgrounds.

\section{METHOD}

\section{Participants}

The present analyses were based on three samples: the Finnish Jyväskylä Longitudinal Study of Personality and
Social Development (JYLS; initial $N=369$ ); the USA Columbia County Longitudinal Study (CCLS; initial $N=856$ ); and the USA Child Development Project (CDP; initial $N=585$ ). Although all three studies included multiple waves of data collection, we restricted the analyses for this study to the two most comparable childhood and early adulthood assessment points in each project: age 8 represents middle childhood in all three projects and ages 27,30 , and 21-26 represent early adulthood in the JYLS, CCLS, and CDP, respectively. Observations were excluded from the final statistical analyses examining differences in the continuity of aggression by childhood parent occupational status if there were missing data for childhood family background or if data were missing for both peer-nominated general childhood aggression and self-reported adult physical aggression. Percentages of observations excluded from the final analyses ranged from 0 for the JYLS to $6.7 \%$ $(n=39)$ and $21.3 \%(n=182)$ for the CDP and CCLS, respectively.

Jyväskylä Longitudinal Study of Personality and Social Development (JYLS). The JYLS is an ongoing longitudinal study, where the same participants have been followed up at 6-8-year intervals from ages 8 to 50 (Pulkkinen, 2006, 2009). Pulkkinen (Pitkänen, 1969) started the study in 1968 , when she randomly selected 12 complete school classes of second grade students (initial $N=369,173$ girls and 196 boys) to the study sample in the town of Jyväskylä, Finland; the initial nonresponse for the study was zero. Most of the children were born in 1959 and were about 8 years old at the baseline. All the JYLS participants were native Finns. Information about children's social behavior (including aggression) was collected using peer nominations and teacher ratings. Data about parental socioeconomic status (parents' occupations) were collected from school records.

Information about the participants' aggression was collected at six time points, but in this study, in addition to at age 8 (1968), we utilized information collected at age 27 (1986). At age 8, there were no missing data for the initial sample $(N=369)$. At age 27 , the mailed Life Situation Questionnaire was returned by 155 women (90\% of the initial sample) and 171 men $(87 \%)$, and 142 women (82\%) and 150 men (77\%) participated in a semi-structured interview (including questions about aggression). The study participants in adulthood have been representative of both the initial sample and the Finnish age-cohort group born in 1959 (Pulkkinen \& Kokko, 2010). Data for self-reported adult physical aggression were missing for 77 participants $(20.9 \%)$ of the initial sample; the respective figures for women and men were $31(17.9 \%)$ and $46(23.5 \%)$. The multiple group structural equation models conducted for this 
paper were estimated using the Mplus statistical program's implementation of full information maximum likelihood (FIML) estimation and included all sample participants $(N=369)$.

Columbia County Longitudinal Study (CCLS). In the 1959-60 school year, almost the entire population of third graders in Columbia County, NY were assessed on peer-nominated aggression (initial $N=856 ; 436$ boys, 420 girls) in an attempt to measure the prevalence of aggression (Eron et al., 1971; Huesmann et al., 2006). Most of the children were born in 1951 and were 8 years old, and the children came from 38 public and private third-grade classrooms in the county. Over $90 \%$ of the initial sample of 856 participants was Caucasian; $51 \%$ were boys. The number of ethnic minorities (i.e., $3 \%$ African American, $<1 \%$ Asian or Pacific Islanders, $<1 \%$ Hispanic) was too small to allow separate analyses. About 4\% of the participants' parents were born outside the USA. The participants came from a broad range of socioeconomic backgrounds $(M=5.01, \mathrm{SD}=2.23$ on a 10-point scale of father's occupational status derived by Eron et al. (1971), based on Warner, Meeker, and Eells' (1960) 7-point scale). Information about aggression was collected at four time points, but for the purposes of this study, we focused on data collected at ages 8 (1960) and 30 (1981). Data for childhood household SES were missing for $182(21.3 \%)$ of the initial study participants, 85 boys $(19.5 \%)$ and 97 girls $(23.1 \%)$.

At age 30 in 1981, 211 women $(50 \%$ of the initial sample) and 198 men (45\%) completed aggression measures as part of a wide-ranging assessment. The reinterviewed CCLS participants differed from the "dropouts" on some dimensions. In the 1981 data collection wave, the mean age 8 aggression score for the total sample of male and female re-interviewed participants was found to be significantly lower than the mean score for drop-outs (i.e., by .17 SDs for the 1981 sample); within sexes, men who were not re-interviewed had higher aggression scores than those who were reinterviewed, but there were no significant differences between re-interviewed and non-re-interviewed women. However, the plots of the distributions and statistics revealed that many of the most highly aggressive participants were re-sampled and there was no substantial restriction of range that might have made it difficult to detect relations between aggression and other variables. There were no significant differences between re-interviewed and non-re-interviewed participants on father's occupational status or level of parent education. Multiple group structural equation models examining the stability of aggression by sample for the CCLS and CDP and by country and by sex included all CCLS sample participants $(N=856)$. Multiple group models examining potential differences in the stability of aggression by childhood SES included 674 (78.7\%) of the initial CCLS study participants (323 females and 351 males). The Mplus program's implementation of FIML estimation is unable to include observations having missing data for the grouping variable used for multiple group structural equation models and therefore excluded 182 CCLS participants having missing data for childhood family SES.

Child Development Project (CDP). The CDP is a multi-site longitudinal study of child development (Dodge et al., 1990). Children were recruited in two cohorts when they entered kindergarten (age 5) in 1987 or 1988 at three USA sites: Knoxville and Nashville, $\mathrm{TN}$ and Bloomington, IN. The children's parents were approached at random during kindergarten preregistration and asked if they would participate in a longitudinal study of child development. About $15 \%$ of children at the targeted schools did not pre-register. These participants were recruited on the first day of school or by subsequent contact. Of those asked, approximately $75 \%$ agreed to participate. The initial sample consisted of 585 families at the first assessment. Boys comprised $52 \%$ of the sample. Eighty-one percent $(81 \%)$ of the sample were European American, 17\% were African American, and $2 \%$ were from other ethnic groups. There were no immigrant families.

For purposes of comparability with the data collection points in the JYLS and CCLS, in this study we included data from seven assessment points in the CDP. When children were age 8 , their classroom peers provided nominations regarding their aggressive behavior. At ages 21-26, participants completed self-report measures related to their own physical aggression during the past month; assessments from these 6 years were aggregated into a single young adulthood composite to be comparable to the composites from the JYLS and CCLS which measured aggressive behaviors during the past 5 years (CCLS) or typically committed (JYLS). Age 8 peer nomination data were available from $452(77.3 \%)$ of the initial 585 participants, and young adult data were available from 482 (82.4\%) of the initial participants. Participants who continued into adulthood did not differ from those who did not on measures of childhood aggression. Data for childhood parent occupational status were available for $580(99.2 \%)$ of the initial participants. Multiple group structural equation models for the stability of aggression by sample for the CDP and CCLS and by country and by sex included 549 participants (268 female and 281 male participants). The Mplus program's implementation of FIML estimation is unable to include observations having missing data for all dependent variables and therefore excluded 36 observations that had missing data for both childhood general aggression and adult physical aggression. Multiple group structural equation models examining 
potential differences in the stability of aggression by childhood parent occupational status included 546 (93.3\%) of the initial CDP study participants (267 girls and 279 boys) and excluded 39 study participants having missing data for childhood background or both dependent variables.

\section{Measures and Variables}

Approach to selection of aggression items. In order to select aggression measures that were comparable across the three data sets, we selected peer nominations of aggression at age 8 and self-reports of property destruction and interpersonal physical aggression in early adulthood. Regarding age 8 peer nominations of aggression, a comparison of the JYLS and CCLS is noteworthy because when Pulkkinen (JYLS) devised her measure of aggression for her doctoral dissertation (Pitkänen, 1969), she adapted several of Eron's peer nomination items (Banta \& Walder, 1961; Walder, Abelson, Eron, Banta, \& Laulicht, 1961; Wiggins \& Winder, 1961), translated them from English to Finnish and then back to English. Later, it turned out that this measure had been used for baseline data collection in the CCLS (Lefkowitz, Eron, Walder, \& Huesmann, 1977). Table I shows the aggression items from childhood and adulthood across the three data sets.

TABLE I. Measures for Childhood Peer-Nominated General Aggression and Adult Self-Reported Physical Aggression by Study

\begin{tabular}{|c|c|}
\hline Study & Measure \\
\hline \multicolumn{2}{|c|}{ Jyväskylä Longitudinal Study of Personality and Social Development (JYLS) } \\
\hline \multicolumn{2}{|c|}{ Age 8 peer-nominated general aggression } \\
\hline & $\begin{array}{l}\text { Which of your classmates may hurt another child when angry, e.g., by hitting, kicking, or } \\
\text { throwing something? }\end{array}$ \\
\hline & Who quarrels with other children even for a slight reason? \\
\hline & $\begin{array}{l}\text { Who easily starts sulking (their look reveals that they are angry although they do not say a } \\
\text { word)? }\end{array}$ \\
\hline & Who kicks pieces of furniture or other objects when angry at something? \\
\hline & Who may attack somebody without any reason? \\
\hline & Who says naughty things to other children even if these had done nothing wrong to him? \\
\hline & Who keeps sneering and making faces at other children? \\
\hline & Who teases others when angry when they do not notice? \\
\hline & Who teases smaller and weaker peers when angry at something? \\
\hline & Who may take other children's possessions? \\
\hline \multicolumn{2}{|c|}{ Adult self-rated physical aggression } \\
\hline & Do you break things? \\
\hline & Do you hit other people? \\
\hline \multicolumn{2}{|c|}{ Columbia County Longitudinal Study (CCLS) } \\
\hline \multicolumn{2}{|c|}{ Age 8 peer-nominated general aggression } \\
\hline & Who does not obey the teacher? \\
\hline & Who often says, "Give me that?" \\
\hline & Who gives dirty looks or sticks out their tongue at other children? \\
\hline & Who makes up stories and lies to get other children into trouble? \\
\hline & Who does things that bother others? \\
\hline & Who starts a fight over nothing? \\
\hline & Who pushes or shoves children? \\
\hline & Who is always getting into trouble? \\
\hline & Who says mean things? \\
\hline & Who takes other children's things without asking? \\
\hline \multicolumn{2}{|c|}{ Adult self-rated physical aggression } \\
\hline & I get angry and smash things \\
\hline & In the past 5 years have you ever slapped or kicked another adult? \\
\hline & How many times? \\
\hline \multicolumn{2}{|c|}{ Child Development Project (CDP) } \\
\hline \multicolumn{2}{|c|}{ Age 8 peer-nominated general aggression } \\
\hline & Who starts fights...says mean things and hits other kids? \\
\hline & Who is mean and bossy...tries to push other kids around to get what they want? \\
\hline & $\begin{array}{l}\text { Who gets mad, even when they shouldn't...like when someone does something to them by } \\
\text { accident? }\end{array}$ \\
\hline \multicolumn{2}{|c|}{ Adult self-rated physical aggression } \\
\hline & Destroys own things \\
\hline & Destroys others' things \\
\hline & How many times have you gotten into a fight or hit someone? \\
\hline
\end{tabular}


In the present study, we selected items for peernominated aggression from the CDP that were most comparable with those used by the JYLS and CCLS. Each item for childhood general aggression was the number of times that a child was nominated by peers in his/her classroom for that item divided by the number of children in the classroom, expressed in percentages. The score used for analyses was the natural $\log$ of the mean of all available items for childhood general aggression.

For adult physical aggression, we identified items in the CCLS and CDP that were most comparable to the two items used by the JYLS to measure self-reported direct physical aggression at age 27. Measures were also selected to best match the age of assessment across the three data sets: Age 27 for the JYLS, age 30 for the CCLS, and ages 21-26 for the CDP. Scale scores for adult physical aggression were computed by summing the response values for the two items. This measure was highly skewed so the natural log of the scale score was used for all statistical analyses.

Jyväskylä Longitudinal Study of Personality and Social Development (JYLS). Aggression at age 8 was a sum score of 10 peer-nominated items, originally presented by Pulkkinen (Pitkänen, 1969; see also Pulkkinen, 1987): for direct offensive verbal aggression (e.g., "Who says nasty things to other children even if these had done nothing wrong to him"), for direct offensive physical aggression (e.g., "Who may attack somebody without any reason"), for direct defensive physical aggression (e.g., "Who may hurt another child when angry, e.g., by hitting, kicking, or throwing something"), for direct defensive verbal aggression (e.g., "Who quarrels with other children even for a slight reason"), for facial expressions of anger (e.g., respectively, "Who easily starts sulking" and "Who keeps sneering and making faces to other children"), and for indirect aggression (e.g., "Who teases others when angry when they do not notice" and "Who kicks pieces of furniture or other objects when angry at something" (see Table I). For peer nomination, a list of names was prepared for each participant with similar pages for each item. Thus, an answer was given for each question on a separate page. The girls' list of names contained the first name and, if necessary, the first letter of the surname of each girl in the class. The boys' list of names contained the name of each boy in the class correspondingly. In the instruction the number of peers to be identified for each question (not themselves) was left relatively undefined, although stress was laid on the importance of at least three names for each question (Pitkänen, 1969, p. 116). The score represents the mean percentage of times the child was nominated by classmates on the 10 items (participants could nominate peers of the same sex; thus, a child's score was: total number of nominations received across the 10 items/number of voters times 10). The Cronbach's alpha was .94 for girls and .96 for boys.

Aggression at age 27 was indicated by two items, one assessing property destruction and one assessing interpersonal physical aggression: (1) "Do you break things?" and (2) "Do you hit other people?" Participants responded to each item along a 3 -point scale: $0=n o t$ at all, $1=$ sometimes, $2=$ often. The indices for the two items (property destruction, interpersonal physical aggression; $r=.33$ ) were summed. Thus, scores on the scale could range from 0 to 4 .

Parent occupational status was based on father's occupation when the participants were 8 years old (mother's occupation was used if she was a sole provider; Pitkänen, Lyyra, \& Pulkkinen, 2005). Occupation was originally coded into three categories: $1=$ non-professional (bluecollar workers, e.g., cleaners, waiters), $2=$ lower professional occupational status (lower white-collar workers, e.g., nurses, engineers), and $3=$ higher professional occupation status (upper white-collar workers, e.g., managers, physicians). This resulted in $29 \%$ of the sample being classified as having professional occupational status. Since about $70 \%$ of the Finnish fathers had nonprofessional occupations (typical in the historical context of 1959 in Finland) we decided to use only two categories, non-professional and professional or supervisory parent occupational status, in all three samples. For comparative purposes, about $70 \%$ of the USA samples were also classified as non-professional participants. The label "nonprofessional" is used for clarity but one should note that the fathers in this category had various occupations, some of which could be better described, particularly in the USA samples, using a broader category of blue-collar, unskilled, and skilled occupations.

\section{Columbia County Longitudinal Study (CCLS).}

Peer-nominated aggression was assessed at age 8 using a peer-nomination procedure developed by Eron et al. (1971), who defined aggression as "an act whose goal response is injury to another object" (p. 30). The 10 peernominated aggression items cover physical (e.g., "Who pushes and shoves other children?"), verbal (e.g., "Who says mean things?"), acquisitive (e.g., "Who takes other children's things without asking?"), and indirect (e.g., "Who makes up stories and lies to get other children into trouble?") aggressive acts (see Table I). The score represents the proportion of times the child was nominated by classmates on the 10 items (participants could nominate peers of either sex; thus, a child's score was: total number of nominations received across the 10 items/number of classmates times 10). This measure is described in detail elsewhere (Eron et al., 1971; Huesmann et al., 1984), has been widely used, and has an $\alpha=.90$ or higher in multiple cross-national samples (Huesmann \& Eron, 1986). 
Aggression at age 30 was indicated by two items (one assessing property destruction, and one assessing interpersonal physical aggression) for which response options were re-coded for consistency with the other two studies: (1) "I get angry and smash things" (original response options were $0=$ never to $4=$ almost always; re-coded to $0=$ never, $1=$ seldom/sometimes, $2=$ often/ almost always); and (2) "In the past 5 years, have you ever slapped or kicked another adult?"; "if yes, how many times?" (original response scale was $1=$ once to $4=$ four or more times; re-coded to $0=$ no/never, $1=$ onceltwice, $2=$ three times/four or more times). The indices for the two items (property destruction, interpersonal physical aggression; $r=.23$ ) were summed. Thus, scores on the scale could range from 0 to 4 .

Parent occupational status was based on father's occupation, which was collected from parent interviews when the child was 8 years of age. We used an occupational coding scale developed by Warner et al. (1960) and adapted by Eron et al. (1971). Occupations were coded on a 10 -point scale $(0=$ laborers to $9=$ professionals). We re-coded Warner's index as follows: 1 = non-professional (laborers, unskilled workers, semi-skilled workers, proprietors of small businesses, skilled workers, clerical workers) and $2=$ professional occupational status (semi-professionals, officers of large businesses, professionals, proprietors of large businesses). This resulted in $30 \%$ of the sample being classified as having professional occupational status.

Child Development Project (CDP). Aggression at age 8 was assessed through sociometric interviews following the protocol described by Coie, Dodge, and Coppotelli (1982). These interviews were conducted during the winter of the school year in all classrooms in which at least $70 \%$ of children's parents gave consent. Children were shown a class roster and were asked to name up to three peers who fit each of three behavioral descriptors: "starts fights, says mean things to other kids, or pushes and hits kids"; "is mean to other kids to get what they want," and "gets mad even when they shouldn't...like when someone does something to them by accident" (see Table I). The score used for analyses is the average percentage of times that a child was nominated as being aggressive by his or her classmates. The Cronbach's alpha was .82 for girls and .90 for boys.

Annually when participants were ages 21-24, they completed the Young Adult Self Report (YASR; Achenbach \& Rescorla, 2003). Two items (i.e., "Damage or destroy own things" and "Damage or destroy others' things") from the YASR were rated on a 3-point scale $(0=$ not true, $1=$ sometimes true, $2=$ very true or often true). To achieve comparability with the JYLS and CCLS property destruction item, we took the maximum value on these two items across the 4 years (ages 21-24). For the interpersonal aggression item, participants at ages 23-26 were asked, "How many times have you gotten into a fight or hit someone?" Responses were coded as $0=$ never, $1=$ once/twice, and $2=$ three or more times . The two indices (property destruction, interpersonal physical aggression; $r=.28$ ) were summed. Thus, scores on the scale could range from 0 to 4 .

Parent occupational status was based on father's occupation using the Hollingshead (1979) occupational system, which ranges from $1=$ menial service workers to $9=$ business executives and major professionals such as doctors, lawyers, and scientists. When there was no father in the family, the mother's occupational status was used instead. For the purposes of the present analyses, we re-coded occupations into two categories: $1=$ nonprofessional (farm laborers/menial service workers, unskilled workers, semi-skilled workers, small business owners, clerical/sales workers, minor professionals) and $2=$ professional parent occupational status (administrators, higher executives, proprietors of large businesses, and major professionals). This resulted in $26 \%$ of the sample being classified as having professional parent occupational status.

\section{Data Analysis}

We first present descriptive statistics for the key variables for all three studies - the Finnish JYLS, and the American CCLS and CDP studies. Then we use multiple group structural equation modeling to explore whether the continuity of aggression from middle childhood to adulthood differed by study. The samples for the three studies differed by country (USA vs. Finland) and by birth year (1951 for the CCLS, 1959 for the JYLS, and 1982-1983 for the CDP). After that we examine whether continuity differs by sex or by childhood parent occupational status and the extent to which associations varied between the USA samples and between Finnish and the American samples.

For the structural equation model (SEM) analyses, parameters were estimated using FIML estimation procedures to handle missing data (Graham, 2009). The Mplus program's (Muthén \& Muthén, 1998-2010) implementation of FIML estimation uses all available data from each observation for the estimation of model parameters. Observations that are missing data for all included dependent variables - peer-nominated childhood general aggression and self-reported adult physical aggression - are not included by Mplus in statistical analyses performed using FIML estimation procedures. For the first series of multigroup SEM analyses examining the stability of aggression across the three samples-USA CCLS sample, USA CDP sample, and 
Finland JYLS sample - all observations were included for the JYLS and CCLS which both have complete data for childhood general aggression. For the CDP, 36 observations having missing data for both childhood and adult aggression were excluded from the statistical analyses. For the multiple group structural equal analyses by childhood parent occupational status, observations were also excluded by the Mplus program if they had missing data for the grouping variable childhood SES ( $N=182$ for the CCLS and $N=5$ for the CDP sample). Percentages of sample observations included in the analyses of the stability of aggression by childhood parent occupational status ranged from $78.7 \%$ for the CCLS $(N=674)$ to $93.3 \%(N=546)$ and $100 \%$ $(N=369)$ for the CDP and JYLS, respectively. Sample sizes for subgroups were examined for each set of multiple group analyses to insure that all subgroups included at least 10-20 observations for each estimated parameter per conventionally recommended guidelines (Kline, 2005).

Overall goodness of fit for the structural equation models was evaluated using Bentler's (1990) normed comparative fit index (CFI), the Tucker Lewis index (TLI), and the root mean square error of approximation (RMSEA). CFI and TLI values of at least .95 and RMSEA values of .05 or less were defined as indicating good model fit (Hu \& Bentler, 1999). Multiple fit statistics were used because each has associated strengths and weakness and there is no consensus regarding any single best index for ascertaining the lack of fit of a model to the observed data. Nested structural models were compared using the Satorra-Bentler scaled difference chi-square test $\left(\Delta \mathrm{SB} \chi^{2}\right.$; Satorra \& Bentler, 2001). ${ }^{1}$ A significant chi-square difference value indicates a significant loss of fit by constraining the structural pathways to be equal.

Statistical analyses for descriptive statistics and correlations were conducted using the SAS statistical software package (version 9.2; SAS Institute, Inc., Cary, NC). The Mplus statistical software package was used to conduct all SEM analyses (version 6; Muthén \& Muthén, 1998-2010).

\section{RESULTS}

\section{Preliminary Analyses}

We began by examining descriptive statistics (Table II) and correlations among the key variables within each study (Table III). The bivariate correlations in Table III

\footnotetext{
${ }^{1} \Delta \mathrm{SB} \chi^{2}$ is the Satorra-Bentler scaled chi-square difference test used to test for differences in nested structural equation models estimated with full information maximum likelihood.
}

showed no significant relation between age 8 aggression and adult aggression for the Finnish study, but showed significant relations for both of the American studies. This pattern was essentially the same for both male and female participants, with the exception that in the CCLS, for female participants, the relation between childhood and early adulthood aggression approached significance $(r=.12, P<.10)$. The bivariate correlations also suggest that the continuity of aggression may differ by childhood parent occupational status for the two USA studies: Age 8 aggression was significantly correlated with adult physical aggression for CCLS and CDP study participants from non-professional childhood occupational backgrounds, but not for participants from professional childhood occupational backgrounds. There is also preliminary evidence for differences by country: childhood aggression was not significantly correlated with adult physical aggression for Finnish study participants at either level of childhood parent occupational status.

\section{Continuity of Aggression by Country, Sex, and Childhood Parent Occupational Status \\ Continuity of aggression by country. We used} the simple structural equation model diagrammed in Figure 1 to estimate the continuity of aggression from childhood to adulthood. We first estimated the parameters of a three group model where the structural paths for continuity of childhood aggression to adult physical aggression for the two American studies were constrained to be equal. Then we compared the fit of this model with the fit of a saturated model in which the paths were free to vary across all three studies. Sex was included in these models as a covariate. The fit of the model that constrained the paths for the American studies to be equal and freely estimated that for the JYLS was not significantly worse than that for the unconstrained model and fit the observed data well, $\Delta \mathrm{SB} \chi^{2}(1)=0.128$, $P=.720 ; \quad \mathrm{CFI}=1.00 ; \quad \mathrm{TLI}=1.00 ; \quad \mathrm{RMSEA}=0.000$, suggesting that the continuity of aggression did not differ significantly across the two American studies. Child aggression significantly predicted adult physical aggression in both the CCLS $(B=.08, \beta=.17, P=.000)$ and the $\operatorname{CDP}(B=.08, \beta=.21, P=.000)$ studies, but not in the JYLS $(B=.01, \beta=.02, P=.787)$. Constraining the structural path for the Finnish JYLS to be equal to those for the two American studies produced a significantly worse fit of the model to the observed data, $\Delta \mathrm{SB} \chi^{2}(2)=6.56, P=.038 ; \quad \mathrm{CFI}=0.96$; TLI $=0.82$; RMSEA $=0.062$, confirming previous findings of differences in the continuity of aggression by country for samples from the USA and Finland (Kokko et al., 2009). Thus, this first set of models indicated that childhood general aggression significantly and equally predicts adult physical aggression in both 
TABLE II. Descriptive Sample Statistics for Measures of Interest in the Three Studies

\begin{tabular}{|c|c|c|c|c|c|c|}
\hline & \multicolumn{2}{|c|}{ Finnish JYLS $(N=369)$} & \multicolumn{2}{|c|}{ USA CCLS $(N=856)$} & \multicolumn{2}{|c|}{ USA CDP $(N=585)$} \\
\hline & Mean & SD & Mean & SD & Mean & SD \\
\hline Percentage of male participants & $53 \%$ & & $51 \%$ & & $52 \%$ & \\
\hline \multicolumn{7}{|l|}{ Childhood parent occupational status } \\
\hline Non-professional (percent) & $71 \%$ & & $70 \%$ & & $74 \%$ & \\
\hline Professional (percent) & $29 \%$ & & $30 \%$ & & $26 \%$ & \\
\hline Age 8 peer-nominated general aggression ${ }^{\mathrm{a}}$ & 18.37 & 14.79 & 12.73 & 14.00 & 10.51 & 12.91 \\
\hline Adult self-reported physical aggression ${ }^{\mathrm{b}}$ & 0.23 & 0.54 & 0.69 & 0.88 & 0.45 & 0.82 \\
\hline
\end{tabular}

${ }^{a}$ The scale represents the average percentage of times that a child was nominated as being aggressive by his/her peers.

${ }^{\mathrm{b}}$ The scale ranges from 0 to 4 .

American studies but does not predict adult physical aggression for the Finnish JYLS study participants.

Continuity of aggression by country and sex. Our second set of models examined whether these relations differed by sex and again explored potential differences by study and country. We first compared the fit of a model in which the structural paths were constrained to be equal for male and female participants within each with the fit of a model in which the structural paths were free to vary across sex for each of the three data sets. Separate multiple group models were first conducted for each study to assess potential differences by sex within each sample. The fit of the model in which the paths were constrained to be equal across sex was not significantly worse than the fit of the unconstrained model for any of the three samples (JYLS: $\Delta \mathrm{SB} \chi^{2}$

TABLE III. Correlations Between Age 8 Peer-Nominated General Childhood Aggression and Adult Self-Reported Physical Aggression by Study and Stratified by Childhood Parent Occupational Status and Sex for the JYLS, CCLS, and CDP

\begin{tabular}{lccc}
\hline & JYLS & CCLS & CDP \\
\hline Full sample & .02 & $.20^{* * *}$ & $.22^{* * *}$ \\
$N$ & 292 & 391 & 385 \\
Correlations by sex & & & \\
$\quad$ Males & .07 & $.24^{* * *}$ & $.21^{* *}$ \\
$N$ & 150 & 192 & 193 \\
Females & -.05 & $.12^{\dagger}$ & $.17^{*}$ \\
$N$ & 142 & 199 & 192 \\
Correlations by parent occupational status & & \\
$\quad$ Non-professional & -.02 & $.23^{* * *}$ & $.28^{* * *}$ \\
$N$ & 203 & 242 & 275 \\
Professional & .09 & .16 & -.04 \\
$N$ & 89 & 98 & 119 \\
\hline
\end{tabular}

Note. Both aggression measures were natural-log transformed for this analysis.

${ }^{\dagger} P<.10$.

${ }^{*} P<.05$.

${ }^{* *} P<.01$.

${ }^{* * *} P<.001$
$(1)=0.71, P=.40$; CCLS: $\Delta \mathrm{SB} \chi^{2}(1)=2.10, P=.147$; CDP: $\left.\Delta \mathrm{SB} \chi^{2}(1)=0.34, P=.558\right)$. Thus, we cannot conclude that continuity of aggression is different for males and females in any samples. However, this conclusion must be treated cautiously in regard to the CCLS study because, as shown in Table III, childhood aggression is correlated with adult aggression more strongly for males than females $(r=.24$ vs. $r=.12$, $z$ difference $=2.80, P<.01)$. From this, we would conclude that the continuity of aggression from childhood to adulthood may differ for males and females in the CCLS study when it is considered in isolation without any consideration of potential confounders which could bias estimates of unadjusted bivariate correlation.

Continuity of aggression by family of origin occupational status within and across studies. We next examined whether the continuity of aggression differed by level of childhood parent occupational status within each study by comparing the fit of a model in

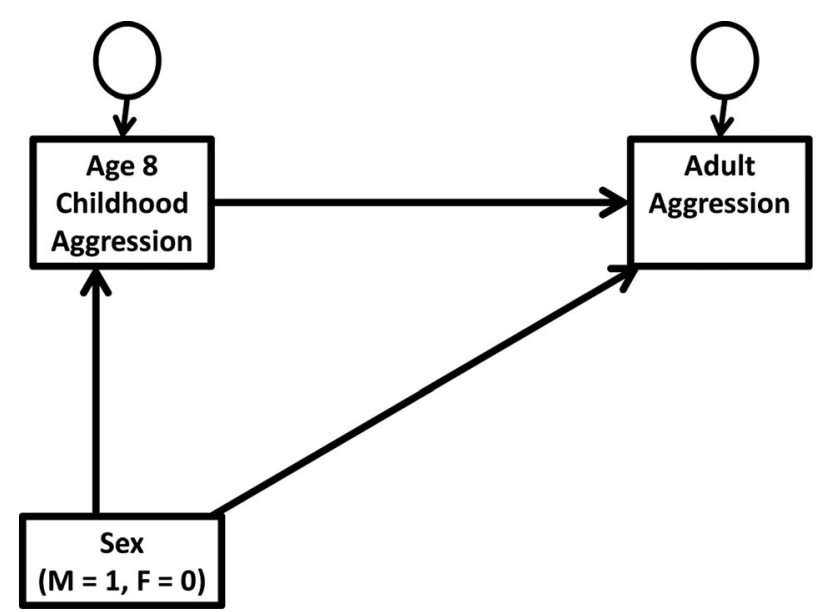

Fig. 1. A diagram of the structural equation model used to estimate continuity of aggression from childhood to adulthood controlling for sex effects on aggression. 
which paths were constrained to be equal for the professional and non-professional occupational groups with the fit of a model in which these paths were free to vary across the two groups. The constrained model fitted no worse than the unconstrained model in Finland, $\Delta \mathrm{SB} \chi^{2}(1)=0.440, P=.507$, indicating that continuity does not vary with parent occupational status in that country. For both levels of occupational status there was no evidence of continuity. For the American CDP sample, the constrained model did fit worse than the unconstrained model, $\Delta \mathrm{SB} \chi^{2}(1)=7.639, P=.006$, with significant continuity for the children who were from the non-professional family background $(B=.10, \beta=.26$, $P=.000$ ) and no significant continuity for the children from the professional family background. For the USA CCLS sample, as in Finland, the constrained model fitted no worse than the unconstrained model, $\Delta \mathrm{SB} \chi^{2}$ $(1)=0.184, P=.668$, indicating that there was no significant difference in continuity estimates for the children from non-professional and professional family occupational backgrounds.

We next used a four-group model, with subgroups for non-professional and professional childhood parent occupational backgrounds for the CDP and CCLS samples, to examine potential differences in the relation between childhood aggression and early adulthood physical aggression by level of childhood parent occupational status for the two American studies. We again included sex in this model as a predictor of both age 8 and adult aggression. The structural equation model is shown in Figure 1. The parameter estimates for the unconstrained four-group model indicated that childhood aggression significantly predicted adult physical aggression for participants who were from non-professional childhood parent occupational backgrounds in both samples but was not significant for CDP and CCLS participants from professional occupational backgrounds. A constrained model equating the structural paths from childhood aggression to early adulthood physical aggression within each occupational group for the two studies fit the observed data as well as the unconstrained model, $\Delta \mathrm{SB} \chi^{2}(2)=2.625, P=.269 ; \mathrm{CFI}=0.994 ; \mathrm{TLI}=0.967$; $\mathrm{RMSEA}=0.032$. Peer-nominated childhood general aggression in the constrained model significantly predicted adult physical aggression for the USA participants who were from non-professional childhood occupational backgrounds $(B=.10, P<.001 ; \beta=.26$ for the CDP and $B=.10, P<.001 ; \beta=.21$ for the CCLS), but was not related to adult physical aggression for those from professional childhood backgrounds $(B=.014, P=.629$; $\beta=.04$ for the CDP and the CCLS).

Finally, we re-estimated the parameters of the model shown in Figure 1 with data added from the Finnish JYLS study to consider whether the continuity of childhood aggression to early adulthood physical aggression differed by national context as well as by childhood parent occupational level. Specifically, we tested the fit of a 6-group model (Study(3) by occupation-level(2)) constraining the continuity of aggression to be equal for the CCLS and CDP participants who were from nonprofessional childhood occupational background, and constraining the continuity of aggression to be equal across all three studies for the participants who were from professional childhood occupational background. The continuity of aggression for JYLS study participants who were from non-professional childhood occupational background was also constrained to be equal to that for those from professional childhood occupational background in Finland and the USA. The path coefficients from this final model are shown in Table IV with tests of

TABLE IV. Unstandardized (B) and Standardized $(\beta)$ Coefficient Estimates From Multiple Group Structural Equation Models for the Continuity of Childhood Age 8 Peer-nominated General Aggression to Adult Self-Reported Physical Aggression by Parent Occupational Status and Study

\begin{tabular}{|c|c|c|c|c|c|c|c|c|c|c|c|c|c|}
\hline \multirow{2}{*}{\multicolumn{2}{|c|}{ Level of Parent Occupational Status }} & \multicolumn{4}{|c|}{ Finnish JYLS } & \multicolumn{4}{|c|}{ USA CCLS } & \multicolumn{4}{|c|}{ USA CDP } \\
\hline & & \multicolumn{2}{|c|}{ Non-Professional } & \multicolumn{2}{|c|}{ Professional } & \multicolumn{2}{|c|}{ Non-Professional } & \multicolumn{2}{|c|}{ Professional } & \multicolumn{2}{|c|}{ Non-Professional } & \multicolumn{2}{|c|}{ Professional } \\
\hline Dependent Variable & Predictor & $B$ & $\beta$ & $B$ & $\beta$ & $B$ & $\beta$ & $B$ & $\beta$ & $B$ & $\beta$ & $B$ & $\beta$ \\
\hline \multirow[t]{2}{*}{ Adult aggression } & Age 8 aggression & 0.01 & .03 & 0.01 & .03 & $0.10^{* * *}$ & $.21^{* * *}$ & 0.01 & .02 & $0.10^{* * *}$ & $.26^{* * *}$ & 0.01 & .03 \\
\hline & $\operatorname{Sex}(M=1, F=0)$ & -0.01 & -.02 & $0.13^{*}$ & $.40^{*}$ & $0.12^{*}$ & $.26^{*}$ & -0.03 & -.07 & 0.05 & .11 & 0.10 & $.27^{\dagger}$ \\
\hline Age 8 aggression & $\operatorname{Sex}(M=1, F=0)$ & -0.05 & -.06 & -0.09 & -.11 & $0.61^{* * *}$ & $.59^{* * *}$ & $0.43^{* *}$ & $.40^{* *}$ & $0.66^{* * *}$ & $.54^{* * *}$ & $0.40^{*}$ & $.38^{*}$ \\
\hline
\end{tabular}

Note. Both aggression measures were natural-log transformed for this analysis. Path coefficients are based on model in which age 8 to adulthood path coefficients for aggression were constrained to be equal for professional participants in three studies and for non-professional participants in the Finnish JYLS. Path coefficients for aggression for the non-professional participants in the two USA samples were also constrained to be equal. The resulting model fit the data well, $\chi^{2}(3)=2.73, P>.60 ; \mathrm{CFI}=1.00 ; \mathrm{RMSEA}=.000$.

${ }^{\dagger} P<.10$

${ }^{*} P<.05$.

${ }^{* *} P<.01$.

${ }^{* * *} P<.001$. 
significance of the path coefficients. This constrained model fits the observed data very well, $\chi^{2}(4)=2.73$, $P>.60 ; \mathrm{CFI}=1.00 ; \mathrm{RMSEA}=.000$. The implication is that there is equal and significant continuity of aggression in the two American samples for participants who are from non-professional parent occupational backgrounds, but there is not significant continuity in the Finnish sample for participants who are from non-professional childhood parent occupational background. The pooled sample used for the final set of multiple group models, including all three data sets, enabled us to estimate these relationships with greater precision, increasing our power to ascertain significant differences in the continuity of aggression by parent occupational status for the two American samples. In contrast, there is no significant continuity of aggression from childhood to early adulthood in either country for participants who are from professional childhood occupational background. These results also support the conclusion that the continuity of aggression for children in the USA does not vary much between participants born in the 1950s and the 1980s, located in different parts of the country, and assessed with different study teams and methods.

\section{DISCUSSION}

The main aim of the present study was to examine continuity from childhood general aggression to early adult physical aggression in the USA and Finland. This report builds on previous findings, based on the comparison between the American CCLS and Finnish JYLS (Kokko et al., 2009), that the continuity in aggression from childhood to mid-adulthood is stronger in the USA than in Finland and that, in the latter, the continuity is higher among males than among females (Kokko et al., 2009). First, we included a new USA sample, namely, the Child Development Project (participants born in the 1980s compared with those born in the 1950s in the CCLS and JYLS), which allowed the investigation of possible cohort differences in the continuity of aggression. Second, we used early adulthood, instead of mid-adulthood, as an endpoint for adult physical aggression. The reason for this was that the three studies had similar aggression items available at more comparable ages at that time point. In their previous study, Kokko et al. (2009) speculated that one of the reasons for the higher continuity observed in the USA sample was due to its use of more severe items for aggression in midadulthood than in the Finnish sample. In the present study, the items were selected carefully so they were nearly identical. Third, we analyzed whether family of origin parent occupational status moderated the continuity of aggression and whether it did so differently in the USA and Finland.

\section{Continuity in Aggression by Country and Sex}

Our results revealed that, as predicted, there was continuity from age 8 general aggression to early adulthood (ages 21-30) physical aggression in the American samples; however, contrary to our hypothesis, no continuity was observed in the Finnish JYLS sample. As predicted, the continuity was similar in the two American samples. These findings imply that there exist country-differences but not cohort-differences within the American studies in the continuity of aggression. In contrast to our expectations, we generally did not find that continuity of aggression was higher among males than females but rather observed equally high continuity (the USA) or no continuity (Finland) between the sexes.

Compared to the previous study (Kokko et al., 2009) in which significant continuity from child general aggression to middle adulthood physical aggression in Finland was obtained, the present findings revealed no significant continuity. It should be noted that both a different age point (age 27 in the current study compared to ages 36 and 42 in the prior study) and a different measure of adult aggression (two items, indicating breaking and hitting, at age 27 compared to Buss and Perry (1992) physical aggression items at ages 36 and 42) was used in the JYLS in this study. The Buss and Perry items captured the feeling that one would like to act physically aggressively whereas in the present study, the items were focused on actual physical aggressiveness. The present finding of similar continuity of aggression from childhood into adulthood among CCLS females and males is also different from what was previously found by Kokko et al. (2009). It should be noted that there we included more severe items for age-30 aggression (i.e., had "choked, punched, or beaten another adult," "slapped or kicked another adult," and "threatened or actually cut someone with a knife or threatened or shot at someone with a gun") than in this study. Severe aggression can be assumed to be most predictable on the basis of early aggression and be more typical of men than women.

\section{Continuity in Aggression by Parent Occupational Status}

This study revealed that the continuity in aggression was only evident among the USA children whose family occupational status was non-professional, including blue-collar, unskilled, and skilled workers. The present items for both childhood and adulthood aggression were carefully selected from a pool of aggression items. They were matched based on the content and also using statistical indicators, such as their descriptive information and factor loadings. Consequently, we maintain that these findings may reflect real cultural differences in the continuity of aggression. There are several theoretical 
explanations for the differences in the continuity of aggression among children from non-professional family occupational backgrounds in the USA and Finland.

First, educational possibilities are more equal across socioeconomic status (SES) groups in Finland than in the USA. College and university education is free and statesupported in Finland, which enhances social mobility. Because educational attainment and staying in school correlate with lower aggression (Henry, Caspi, Moffitt, Harrington, \& Silva, 1999; Underwood \& Coie, 2004) and aggression promotes school failure and lower achievement (Huesmann, Eron, \& Yarmel, 1987), these educational resources might serve as a protective factor that would decrease the likelihood of aggressive Finnish children remaining aggressive by young adulthood. So, we conducted supplemental analyses investigating whether achievement in school might be the real moderator, which might be correlated with parent occupational status in the USA but not in Finland. ${ }^{2}$ We discovered that the participants' family occupational status was equally correlated with their own adult educational achievement in Finland $(r=.284, P<.001)$ and in the SES American samples $(r=.284, P<.001$, for the collapsed sample). Consequently, differing relations of parent occupational status to education or academic achievement does not seem to explain why there is a difference in continuity of aggression for youths who are from non-professional family backgrounds. The most plausible conclusion would seem to be that there is an unidentified element that moderates continuity of aggression but that has not been assessed in this study. It is possible that the school environment functions as such a moderator.

Second, in the USA, perhaps youths from families of higher occupational status who display problematic behavior have more resources to find treatment and social support. Further, families of high occupational status youths may be more likely to be able to deal effectively with schools and juvenile justice systems to deflect the trajectory of aggression a child is displaying. Because equality and social justice are highly valued in the Finnish school system, these kinds of disparities in resources are less evident in Finland. As an example of the social equality, the residential area is the major factor determining the child's school in Finland. The Finnish housing policy has encouraged equality between resi-

\footnotetext{
${ }^{2}$ Adult educational attainment was coded as follows: in the JYLS (at age 27), $1=$ completed primary and secondary schooling but no tertiary education or vocational training; 2 = completed some vocational training; and $3=$ higher vocational qualifications or university and in the CCLS (at age 30) and the CDP (at age 24), 1=a high school diploma or less; $2=$ completed some college or vocational training; and $3=$ completed $a$ Bachelor's degree or higher.
}

dential areas and the schools have a mix of students from different socioeconomic backgrounds. Consequently, differences between schools in student achievement are small (Sahlberg, 2011). Conversely, there is more socioeconomic segregation in the USA, with lower SES children attending schools of lower quality than higher SES children (Organization for Economic Cooperation and Development, 2012).

Third, income equality is much higher in Finland than in the USA (Wilkinson, 2011; Wilkinson \& Pickett, 2010). Wilkinson argues that income inequality is associated with social problems, particularly those that are more common among lower socioeconomic status groups, such as health problems and mistrust. In countries with high inequality of income, different subcultures of behavioral norms and other features related to socioeconomic status may emerge. In Finland, such subcultural differences are almost non-existent. In future studies, it would be important to include factors that might explain the observed relation between child and adult aggression among the lower SES USA children.

The present results regarding differences in the continuity of aggression among individuals from different family occupational backgrounds appear not to be cohort-specific, as the findings were quite similar in the American cohorts born in the 1950s and the 1980s. But it is to be noted that social mobility in the United States has decreased in recent years, with children who grow up in higher income families being 22 times more likely to be in the top $5 \%$ of income earned during adulthood than children who grow up in lower income families (Hertz, 2006).

\section{Limitations and Conclusions}

There are a few issues that need to be considered when interpreting the present results. First, we operationalized adult physical aggression with just two items in each sample. More items might have increased the reliability of the scale. However, the selected items were carefully matched across samples and correlate well with other aggression items assessed in their respective samples in early adulthood. Second, in the JYLS and CCLS samples, adult aggression was measured at one time point, at ages 27 and 30, respectively, whereas in the CDP, it was computed by averaging the aggression scores across ages 21-24 (property destruction) and 23-26 (interpersonal aggression) because differing sets of scale items were included within different waves of data collection. But it should be noted that the combined data for the CDP approximates the 5-year span used for the CCLS item (which referred to the past 5 years) and the more open-ended question used by the JYLS. A further important point to consider in comparing results from the CDP to those from the JYLS and CCLS involves the ages 
of the samples at the time of the adulthood aggression assessments. The CDP participants were ages 21-26, a period during which the prefrontal cortex is in its final stages of development (Jetha \& Segalowitz, 2012). Development of the prefrontal cortex is associated with better emotional regulation and executive function tasks such as planning ahead (Steinberg, 2008; Steinberg et al., 2009), which, in turn, are related to lower levels of aggression (Krämer, Kopyciok, Richter, RodriguezFornells, \& Münte, 2011). Therefore, differences in findings comparing the CDP with the JYLS and CCLS participants, who were slightly older than the CDP participants at the time of the adulthood aggression assessment, may be accounted for by differences in brain development. This concern is mitigated given that the results from the somewhat younger CDP sample and somewhat older CCLS sample in the United States were quite similar, whereas both of the American samples differed from the Finnish sample.

Third, ethnic origin and immigration status are linked to both the income level and occupational status, but for various reasons, we were unable to consider their role in our analyses. In the JYLS and CCLS, there is no or very little variation in the ethnic origin or immigration status of the participants. In the CDP, there were no immigrant families. However, there existed some variation in the ethnic background: about $80 \%$ of the participants were of European American origin and 20\% of African American or other origin. We replicated the analyses on the continuity of aggression from childhood into early adulthood by including the variable for ethnic origin (combining the groups for African Americans and other ethnic subgroups to create an indicator for being a member of ethnic minority group vs. being Caucasian) as a covariate and found that there were minimal changes in the estimated coefficients for the continuity of aggression from middle childhood to early adulthood. This means that the estimated coefficients for the continuity of aggression were not biased when ethnicity was not included in the estimated models.

Fourth, in North America, particularly, students with similar SES backgrounds occupy certain schools. Consequently, the inclusion of the class/school variable in the statistical analyses would have been valuable. We were unable to include school socioeconomic status for all three samples: In the CDP, this information was not available. Despite any differences between schools in parental occupational status when the children were age 8 , children moved on to different junior high and high schools. Of course, it is possible that indices of the overall school context (e.g., financial resources, academic achievement, aggression) could also influence the individual's early adulthood aggression, but these variables were not available at the school level to examine school context effects. We also expect that parent occupational status is more stable over time than the parent occupational composition of children's schools over time. Instead, we included individual family parent occupation status, rather than parent occupation at the school level during middle childhood as an index of family of origin socioeconomic influences on the individual's aggression in early adulthood. Fifth, we acknowledge that there are several other indicators for family socioeconomic status other than parent occupational status, such as parent education and family income (e.g., Bradley \& Corwyn, 2002). In the present study, only parent occupational status was available in all the studies.

Notwithstanding these limitations, we consider the present study an important attempt to identify moderators of continuity of aggression from childhood to adulthood in the USA compared to Finland. The present study samples utilized exceptionally similar items to measure childhood and adult aggression and parent occupational status. The selection of the child aggression items of the JYLS was originally partly based on the already published CCLS items, and the CDP items were matched with these older longitudinal studies. The inclusion of the CDP allowed an examination of potential cohort-differences in the USA. In future research, it would be important to replicate the present findings in the continuity of aggression in still other countries differing in their resources available to support youth development, and including additional factors other than family occupational background that might moderate the degree of continuity of aggression from childhood to adulthood. Other analytic techniques to examine continuity can also be used. For example, it has been previously shown that less than $10 \%$ of children are on a consistently high trajectory for physical aggression from childhood to adolescence (e.g., Tremblay, 2010) and that these children are at the highest risk for later serious violence (e.g., Loeber, Lacourse, \& Homish, 2005). Furthermore, mother's low education and early childbearing have been the strongest risk factors, particularly in boys, for having consistently high aggression throughout childhood (Nagin \& Tremblay, 2001). Consequently, in the future, it would be interesting to examine whether there are cultural differences in this high aggression trajectory and whether family SES plays a role in this continuity.

\section{ACKNOWLEDGMENTS}

This study was conducted by the authors as members of the Collaborative for the Analysis of Pathways from Childhood to Adulthood (CAPCA) funded by the USA National Science Foundation (NSF) grant \# 0818478. The Jyväskylä Longitudinal of Personality and Social Development has been funded by the Academy of 
Finland since the 1970s, most recently by grants to Katja Kokko (Nos. 118316 and 135347) and Lea Pulkkinen (No. 127125). The Columbia County Longitudinal Study has been supported by funding from the Columbia County (NY) Tuberculosis and Health Association and the Hudson (NY) Lions Club (1960 wave); the USA National Institute of Mental Health (1960, 1970, and 1981 waves); and the National Institute of Child Health and Human Development (2000 wave). Leonard Eron, L. Rowell Huesmann, Monroe Lefkowitz, Leopold Walder, and Eric F. Dubow were co-investigators on the Columbia County Longitudinal Study. The Child Development Project has been funded by grants MH42498, MH56961, MH57024, and MH57095 from the USA National Institute of Mental Health, HD30572 from the Eunice Kennedy Shriver National Institute of Child Health and Human Development, and DA016903 from the National Institute on Drug Abuse.

\section{REFERENCES}

Achenbach, T. M., \& Rescorla, L. A. (2003). Manual for the ASEBA adult forms \& profiles. Burlington, VT: University of Vermont, Research Center for Children, Youth, \& Families.

Archer, J. (2004). Sex differences in aggression in real-world settings: A meta-analytic review. Review of General Psychology, 8, 291-322. doi: 10.1037/1089-2680.8.4.291

Archer, J., \& Coyne, S. M. (2005). An integrated review of indirect, relational, and social aggression. Personality and Social Psychology Review, 9, 212-230. doi: 10.1207/s15327957pspr0903_2

Banta, T. J., \& Walder, L. O. (1961). Discriminant validity of a peerrating measure of aggression. Psychological Reports, 9, 573-582. doi: 10.2466/pr0.1961.9.3.573

Bentler, P. M. (1990). Comparative fit indices in structural models. Psychological Bulletin, 107, 238-246. doi: 10.1037/00332909.107.2.238

Bradley, R. H., \& Corwyn, R. F. (2002). Socioeconomic status and child development. Annual Review of Psychology, 53, 371-399. doi: 10.1146/annurev.psych.53.100901.135233

Brendgen, M., Dionne, G., Girard, A., Boivin, M., Vitaro, F., \& Pérusse, D. (2005). Examining genetic and environmental effects on social aggression: A study of 6-year-old twins. Child Development, 76, 930-946. doi: 10.1111/j.1467-8624.2005.00887.x

Buss, A. H., \& Perry, M. (1992). The aggression questionnaire. Journal of Personality and Social Psychology, 63, 452-459. doi: 10.1037/00223514.63.3.452

Cairns, R. B., Cairns, B. D., Neckerman, H. J., Ferguson, L. L., \& Gariépy, J. (1989). Growth and aggression: 1. Childhood to early adolescence. Developmental Psychology, 25, 320-330. doi: 10.1037/0012-1649. 25.2.320

Coie, J. D., Dodge, K. A., \& Coppotelli, H. (1982). Dimensions and types of social status: A cross-age perspective. Developmental Psychology, 18, 557-569. doi: 10.1037/0012-1649.18.4.557

Dodge, K. A., Bates, J. E., \& Pettit, G. S. (1990). Mechanisms in the cycle of violence. Science, 250, 1678-1683. doi: 10.1126/science.2270481

Eley, T. C., Lichtenstein, P., \& Moffitt, T. E. (2003). A longitudinal behavioral genetic analysis of the etiology of aggressive and nonaggressive antisocial behavior. Development and Psychopathology, 15, 383-402. doi: 10.1017/S095457940300021X

Eron, L. D., Walder, L. O., \& Lefkowitz, M. M. (1971). The learning of aggression in children. Boston, MA: Little Brown.
Farrington, D. P., \& West, D. J. (1990). The Cambridge study in delinquent development: A long-term follow-up of 411 London males. In H. J. Kerner \& G. Kaiser (Eds.), Criminality: Personality, behaviour and life history (pp. 115-138). Heidelberg, NY: Springer-Verlag.

Graham, J. W. (2009). Missing data analysis: Making it work in the real world. Annual Review of Psychology, 60, 549-576. doi: 10.1146/ annurev.psych.58.110405.085530

Henry, B., Caspi, A., Moffitt, T. E., Harrington, H., \& Silva, P. A. (1999). Staying in school protects boys with poor self-regulation in childhood from later crime: A longitudinal study. International Journal of Behavioral Development, 23, 1049-1073. doi: 10.1080/016502599383667

Hertz, T. (2006). Understanding mobility in America. Washington, DC: Center for American Progress. Retrieved from http://www.americanprogress.org/wp-content/uploads/issues/2006/04/Hertz_MobilityAnalysis.pdf

Hollingshead, A. B. (1979). Four-factor index of social status. Unpublished manuscript. New Haven, CT: Yale University.

Hu, L. T., \& Bentler, P. M. (1999). Cutoff criteria for fit indexes in covariance structure analysis: Conventional criteria versus new alternatives. Structural Equation Modeling, 6, 1-55. doi: 10.1080/ 10705519909540118

Huesmann, L. R. (2001). Gender differences in the continuity of aggression from childhood to adulthood: Evidence from some recent longitudinal studies. Paper presented at the 2001 G. Stanley Hall Symposium on Gender and Aggression, Williams College, Williams, Massachusetts.

Huesmann, L. R., Dubow, E. F., \& Boxer, P. (2009). Continuity of childhood, adolescent, and early adulthood aggression as predictors of adult criminality and life outcomes: Implications for the adolescentlimited and life-course-persistent models. Aggressive Behavior, 35, 136-149. doi: 10.1002/ab.20300

Huesmann, L. R., Dubow, E. F., Eron, L. D., \& Boxer, P. (2006). Middle childhood family-contextual and personal factors as predictors of adult outcomes. In A. C. Huston \& M. N. Ripke (Eds.), Developmental contexts in middle childhood: Bridges to adolescence and adulthood (pp. 62-86). New York, NY: Cambridge University Press.

Huesmann, L. R., \& Eron, L. D. (Eds.). (1986). Television and the aggressive child: A cross-national comparison. Hillsdale, NJ: Erlbaum.

Huesmann, L. R., Eron, L. D., \& Dubow, E. F. (2002). Childhood predictors of adult criminality: Are all risk factors reflected in childhood aggressiveness? Criminal Behavior and Mental Health, 12, 185-208. doi: $10.1002 / \mathrm{cbm} .496$

Huesmann, L. R., Eron, L. D., Lefkowitz, M. M., \& Walder, L. O. (1984). Stability of aggression over time and generations. Developmental Psychology, 20, 1120-1134. doi: 10.1037/0012-1649.20.6.1120

Huesmann, L. R., Eron, L. D., \& Yarmel, P. W. (1987). Intellectual functioning and aggression. Journal of Personality and Social Psychology, 52, 232-240. doi: 10.1037/0022-3514.52.1.232

Huesmann, L. R., \& Moise, J. F. (1998). The stability and continuity of aggression from early childhood to young adulthood. In D. J. Flannery \& C. F. Huff (Eds.), Youth violence: Prevention, intervention, and social policy (pp. 73-95). Washington, DC: American Psychiatric Press.

Jetha, M. K., \& Segalowitz, S. J. (2012). Adolescent brain development: Implications for behavior. Waltham, MA: Academic Press.

Kline, R. (2005). Principles and practice of structural equation modeling (2nd ed.). New York, NY: The Guilford Press.

Kokko, K., \& Pulkkinen, L. (2005). Stability of aggressive behavior from childhood to middle age in women and men. Aggressive Behavior, 31, 485-497. doi: 10.1002/ab.20063

Kokko, K., Pulkkinen, L., Huesmann, L., Dubow, E., \& Boxer, P. (2009). Intensity of aggression in childhood as a predictor of different forms of adult aggression: A two-country (Finland and United States) analysis. Journal of Research on Adolescence, 19, 9-34. doi: 10.1111/j.15327795.2009.00579.x 
Krämer, U. M., Kopyciok, R. P. J., Richter, S., Rodriguez-Fornells, A., \& Münte, T. F. (2011). The role of executive functions in the control of aggressive behavior. Frontiers in Psychology, 2, 1-10. doi: 10.3389/ fpsyg.2011.00152

Lefkowitz, M. M., Eron, L. D., Walder, L. O., \& Huesmann, L. R. (1977). Growing up to be violent: A longitudinal study of the development of aggression. Elmsford, NY: Pergamon Press.

Loeber, R., Lacourse, E., \& Homish, D. L. (2005). Homicide, violence, and developmental trajectories. In R. E. Tremblay, W. W. Hartup, \& J. Archer (Eds.), Developmental origins of aggression (pp. 202-219). New York, NY: The Guilford Press.

Lynch, J. W., Kaplan, G. A., \& Salonen, J. T. (1997). Why do poor people behave poorly? Variation in adult health behaviours and psychosocial characteristics by stages of the socioeconomic lifecourse. Social Science and Medicine, 44, 809-819. doi: 10.1016/S0277-9536(96) 00191-8

Magnusson, D. (1988). Individual development from an interactional perspective: A longitudinal study. Hillsdale, NJ: Lawrence Erlbaum Associates.

Muthén, L. K., \& Muthén, B. O. (1998-2010). Mplus user's guide (6th ed.). Los Angeles, CA: Muthén \& Muthén.

Nagin, D. S., \& Tremblay, R. E. (2001). Parental and early childhood predictors of persistent physical aggression in boys from kindergarten to high school. Archives of General Psychiatry, 58, 389-394. doi: 10.1001/archpsyc.58.4.389

Olweus, D. (1979). Stability of aggressive reaction patterns in males: A review. Psychological Bulletin, 85, 852-875. doi: 10.1037/00332909.86.4.852

Organization for Economic Cooperation and Development. (2011). Education at a Glance 2011: OECD Indicators. OECD Publishing. Retrieved from http://dx.doi.org/10.1787/eag-2011-en

Organization for Economic Cooperation and Development. (2012). Education at a Glance 2012: OECD Indicators. OECD Publishing. Retrieved from http://www.oecd.org/edu/eag2012.htm

Pitkänen, L. (1969). Descriptive model of aggression and nonaggression with applications to children's behaviour. Jyväskylä Studies in Education, Psychology and Social Research, Whole Nr. 19, University of Jyväskylä, Finland.

Pitkänen-Pulkkinen, L. (1981). Long-term studies on the characteristics of aggressive and non-aggressive juveniles. In P. F. Brain \& D. Benton (Eds.), Multidisciplinary approaches to aggression research (pp. 225243). Amsterdam, the Netherlands: Elsevier/North-Holland Biomedical Press.

Pitkänen, T., Lyyra, A. L., \& Pulkkinen, L. (2005). Age of onset of drinking and the use of alcohol in adulthood: A follow-up study from age 8-42 for females and males. Addiction, 100, 652-661. doi: 10.1111/j.13600443.2005.01053.x

Pulkkinen, L. (1987). Offensive and defensive aggression in humans: A longitudinal perspective. Aggressive Behavior, 13, 197-212. doi: 10.1002/1098-2337(1987)13:4<197::AID-AB2480130404>3.0. CO;2-E

Pulkkinen, L. (2006). The Jyväskylä longitudinal study of personality and social development. In L. Pulkkinen, J. Kaprio, \& R. J. Rose (Eds.), Socioemotional development and health from adolescence to adulthood (pp. 29-55). New York, NY: Cambridge University Press.

Pulkkinen, L. (2009). Personality-A resource or risk for successful development. Scandinavian Journal of Psychology, 50, 602-610. doi: 10.1111/j.1467-9450.2009.00774.x
Pulkkinen, L., \& Kokko, K. (Eds.). (2010). Keski-ikä elämänvaiheena [Middle age as a stage of life]. Psykologian laitoksen julkaisuja, Nro. 352. Jyväskylä, Finland: Jyväskylän yliopisto (Including an English abstract.).

Pulkkinen, L., \& Pitkänen, T. (1993). Continuities in aggressive behavior from childhood to adulthood. Aggressive Behavior, 19, 249-263. doi: 10.1002/1098-2337(1993)19:4<249::AID-AB2480190402>3.0. $\mathrm{CO} ; 2-\mathrm{I}$

Sahlberg, P. (2011). Finnish lessons: What can the world learn from educational change in Finland? New York, NY: Teachers College, Columbia University.

Sampson, R. J., \& Laub, J. H. (2003). Life-course desisters? Trajectories of crime among delinquent boys followed to age 70. Criminology, 41, 555-592. doi: 10.1111/j.1745-9125.2003.tb00997.x

Satorra, A., \& Bentler, P. M. (2001). A scaled difference chi-square test statistic for moment structure analysis. Psychometrika, 66, 507-514. doi: 10.1007/BF02296192

Steinberg, L. (2008). A social neuroscience perspective on adolescent risk-taking. Developmental Review, 28, 78-106. doi: 10.1016/j. dr.2007.08.002

Steinberg, L., Graham, S., O’Brien, L., Woolard, J., Cauffman, E., \& Banich, M. (2009). Age differences in future orientation and delay discounting. Child Development, 80, 28-44. doi: 10.1111/j.14678624.2008.01244.x

Tremblay, R. E. (2010). Developmental origins of disruptive behavior problems: The "original sin" hypothesis, epigenetics and their consequences for prevention. Journal of Child Psychology and Psychiatry, 51, 341-367. doi: 10.1111/j.1469-7610.2010.02211.x

Tremblay, R. E. (2012). The development of physical aggression. Encyclopedia on early childhood development. CEED/SKC-ECD Retrieved from http://www.child-encyclopedia.com/en-ca/recherche. $\mathrm{html}$ ?q= tremblay

Underwood, M. K., \& Coie, J. D. (2004). Future directions and priorities for prevention and intervention. In M. Putallaz \& K. L. Bierman (Eds.), Aggression antisocial behavior, and violence among girls: A developmental perspective (pp. 289-301). New York, NY: Guilford Press.

United Nations Office on Drugs and Crime. (2013). Homicide statistics, 2013. Retrieved from http://www.unodc.org/unodc/en/data-and-analysis/homicide.html

Vierikko, E., Pulkkinen, L., Kaprio, J., \& Rose, R. J. (2006). Genetic and environmental sources of continuity and change in teacher-rated aggression during early adolescence. Aggressive Behavior, 32, 308320. doi: $10.1002 / \mathrm{ab} .20117$

Walder, L., Abelson, R., Eron, L., Banta, T., \& Laulicht, J. (1961). Development of a peer-rating measure of aggression. Psychological Reports, 9, 497-556.

Warner, W. L., Meeker, M., \& Eells, K. (1960). Social class in America. New York, NY: Harcourt.

Wiggins, J. S., \& Winder, C. L. (1961). The peer nomination inventory: An empirically derived sociometric measure of adjustment in preadolescent boys. Psychological Reports, 9, 643-677.

Wilkinson, R. (2011). Inequality and the wellbeing of adults and children in rich countries. In C. Clouder, B. Heys, M. Matthes, \& P. Sullivan (Eds.), Improving the quality of childhood in Europe 2011 (pp. 62-79). Brussels, Belgium: ECSWE.

Wilkinson, R., \& Pickett, K. (2010). The spirit level: Why equality is better for everyone. London: Penguin Books. 